\title{
Penumbral Imaging-Based Thrombolysis with Tenecteplase Is Feasible up to 24 Hours after Symptom Onset
}

Mahesh Kate, ${ }^{\text {a }}$ Robert Wannamaker, ${ }^{\text {a }}$ Harsha Kamble, ${ }^{\text {a }}$ Parnian Riaz, ${ }^{\text {a }}$ Laura C. Gioia, ${ }^{\text {a } B r i a n ~ B u c k, ~}{ }^{\text {a }}$

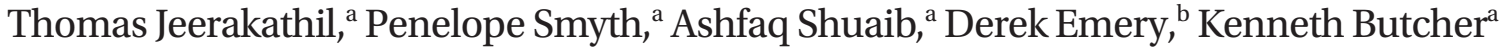

${ }^{a}$ Division of Neurology, Department of Medicine, University of Alberta, Edmonton, $A B$, Canada

${ }^{b}$ Department of Radiology and Diagnostic Imaging, University of Alberta, Edmonton, $A B$, Canada

J Stroke 2018;20(1):122-130

https://doi.org/10.5853/jos.2017.00178

In the article, there is a mistake of last two authors' order. The corrected order is 'Mahesh Kate,


Jeerakathil, ${ }^{a}$ Penelope Smyth, ${ }^{a}$ Ashfaq Shuaib, ${ }^{a}$ Derek Emery ${ }^{\mathrm{b}}$, Kenneth Butcher ${ }^{\mathrm{a}}$.'

We apologize for any inconvenience that this may have caused. 